\title{
Correction to: Studying the Composition and Mineralogy of the Hermean Surface with the Mercury Radiometer and Thermal Infrared Spectrometer (MERTIS) for the BepiColombo Mission: An Update
}

H. Hiesinger' ${ }^{1}$ J. Helbert ${ }^{2}$ - G. Alemanno ${ }^{2}$ - K.E. Bauch ${ }^{1}$ • M. D'Amore ' $^{\text {. }}$ A. Maturilli ${ }^{2}$ - A. Morlok ${ }^{1}$ - M.P. Reitze ${ }^{1}$ - C. Stangarone ${ }^{2}$ - A.N. Stojic ${ }^{1}$. I. Varatharajan ${ }^{2}$ - I. Weber ${ }^{1}$ - the MERTIS Co-I Team ${ }^{3}$

Accepted: 2 December 2020 / Published online: 14 December 2020

(c) Springer Nature B.V. 2020

Correction to: Space Sci. Rev. (2020) 216: 110

https://doi.org/10.1007/s11214-020-00732-4

The affiliations of several authors in the published article are not given correctly. Please find in this document the correct author affiliations that should be regarded as final by the reader.

Publisher's Note Springer Nature remains neutral with regard to jurisdictional claims in published maps and institutional affiliations.

The BepiColombo mission to Mercury

Edited by Johannes Benkhoff, Go Murakami and Ayako Matsuoka

The original article can be found online at https://doi.org/10.1007/s11214-020-00732-4

$\triangle$ H. Hiesinger

1 Institut für Planetologie, Westfälische Wilhelms-Universität Münster, Wilhelm-Klemm-Str. 10, 48149 Münster, Germany

2 Institut für Planetenforschung, Deutsches Zentrum für Luft- und Raumfahrt (DLR), Rutherfordstr. 2, 12489 Berlin, Germany

3 https://www.uni-muenster.de/Planetology/ifp/research/geologischeplanetologie/MERTIS.html 